\title{
Analisis Kompetensi Profesional Guru Melalui Penggunaan Media Pembelajaran Berbasis Information Technology
}

\author{
Rose Fitria Lutfiana \\ rose@umm.ac.id \\ Program Studi Pendidikan Pancasila dan Kewarganegaraan \\ Fakultas Keguruan dan Ilmu Pendidikan \\ Universitas Muhammadiyah Malang
}

\begin{abstract}
Abstrak
Tujuan dari penelitian ini yaitu menganalisis media pembelajaran yang memanfaatkan information technology agar bisa meningkatkan kompetensi profesional di SMP Muhammadiyah 8 Batu. Pendekatan yang digunakan yaitu kualitatif dan jenis penelitiannya berupa deskriptif. Lokasi penelitian di SMP Muhammadiyah 8 Batu selama tiga bulan yaitu pada Agustus-November 2020. Informan meliputi kepala sekolah serta semua guru di SMP Muhammadiyah 8 Batu. Proses pengumpulan data yang digunakan meliputi studi dokumentasi, wawancara dan observasi. Untuk proses analisis data yang dipilih adalah teknik analisis Milles Huberman yang terdiri dari empat tahap yaitu pengumpulan data, reduksi data, penyajian data dan kesimpulan. Hasil penelitian yang diperoleh yaitu: (a) guru mampu melakukan pengelolaan pembelajaran berbasis information technology seperti edmodo, office 365, google classroom, dan WAG; dan (b) guru mampu merancang berbagai media pembelajaran berbasis information technology yang digunakan dalam pembelajaran seperti membuat video pembelajaran, membuat kuis dengan aplikasi quizzes dan PPT.
\end{abstract}

Kata kunci: media pembelajaran, Information technology, kompetensi professional.

\begin{abstract}
The purpose of this research is to analyze learning media that utilize information technology in order to improve professional competence at SMP Muhammadiyah 8 Batu. The approach used is qualitative and the type of research is descriptive. The research location was at SMP Muhammadiyah 8 Batu for three months, namely August - November 2020. The informants included the principal and all teachers at SMP Muhammadiyah 8 Batu. The data collection process used includes documentation study, interview and observation. For the data analysis process chosen was the Milles Huberman analysis technique which consisted of four stages, namely data collection, data reduction, data presentation and conclusions. The results obtained are: (a) teachers are able to manage information technology-based learning such as edmodo, office 365, google classroom, and WAG; and (b) the teacher is able to design various information technology-based learning media used in learning such as making instructional videos, making quizzes with the quizzes and PPT applications.
\end{abstract}

Keyword: learning media, information technology, professional competence 
Jurnal PINUS: Jurnal Penelitian Inovasi Pembelajaran, 7 (1), 2021, Rose Fitria Lutfiana

\section{PENDAHULUAN}

Salah satu hal krusial yang mempengaruhi kualitas sistem pendidikan di Indonesia yaitu faktor kompetensi guru. Seperti yang kita tau, pada dasarnya kompetensi bisa menjadi sebuah bayangan atau ilustrasi tentang tanggung jawab seseorang terhadap apa yang semestinya dilakukan. Dalam konteks kompetensi dalam bidang pendidikan, guru sebagai pendidik mempunyai kewajiban dalam penguasaan tentang bidang ilmu yang digelutinya, berkarakter, dan menguasai teknologi serta mampu beradaptasi dengan tuntutan zaman. Terkait kompetensi guru tersebut secara yuridis formal terdapat dalam Undang-Undang Nomor 14 Tahun 2005 tentang Guru dan Dosen, dalam undangundang menekankan adanya empat kompetensi guru profesional yang wajib dimiliki yang meliputi kompetensi pedagogi, kompetensi profesional, kompetensi kepribadian dan kompetensi sosial. Menurut Wahyudi (2012) seorang guru bisa dikatakan sebagai guru profesional jika dia bisa memahami dan memaksimalkan potensi yang dimiliki dalam melaksanakan berbagai tugas yang diembannya sehari-hari. Hakikatnya guru tidak hanya mempunyai tugas untuk mendidik ataupun mengajar, tetapi lebih dari itu guru mempunyai tugas untuk membimbing, mengarahkan, melatih, menilai dan mengevaluasi peserta didik. Sejalan dengan pendapat Wahyudi, Fitriani (2017) menyatakan bahwa dalam kaitannya dengan kewenangan profesional yang melekat pada diri guru maka guru diharuskan memiliki paket lengkap kompetensi profesional sesuai dengan Undang-Undang Nomor 14 Tahun 2005.

Dudung (2018) menyatakan bahwa secara umum kompetensi profesional dapat dikaji dari berbagai hal antara lain: (1) guru mempunyai kemampuan untuk memahami dan mengimplementasikan landasan kependidikan yang terdiri dari 4 hal yaitu filosofi, psikologis, sosiologis, dan kultural; (2) guru mempunyai kemampuan untuk memahami dan mengimplementasi-kan teori belajar yang sesuai dengan tahapan peserta didik; (3) guru mempunyai kemampuan menguasai dan mengembangkan bidang keahlian secara bertanggung jawab; (4) guru mempunyai kemampuan memahami dan meng-implementasikan metode pembelajaran sesuai dengan tuntutan zaman; (5) guru mempunyai kemampuan meng-implementasikan berbagai media pembelajaran dan juga sumber belajar yang relevan bagi peserta didik; (6) guru mempunyai kemampuan merancang dan mengimplementasikan program pembelajaran; (7) guru mempunyai kemampuan melakukan proses evaluasi pembelajaran; dan (8) guru mempunyai kemampuan membentuk kepribadian atau karakter peserta didik.

$$
\text { Marwiyah dkk }
$$

memberikan penjabaran lebih lanjut tentang kompetensi guru profesional, bahwa terdapat tiga hal yang bisa dijadikan indikator yaitu expert (keahlian) dalam kerangka profesionalitas seorang guru, mempunyai passion atau panggilan hidup menjadi guru dan memiliki tanggung jawab untuk kemajuan pendidikan. Expert (keahlian) 
Jurnal PINUS: Jurnal Penelitian Inovasi Pembelajaran, 7 (1), 2021, Rose Fitria Lutfiana

guru berkaitan dengan kompetensi pedagogi dan kompetensi profesional.

Terdapat berbagai cara yang dapat dikembangkan untuk meningkatkan pembelajaran yaitu berorientasi pada penciptaan iklim pembelajaran yang kondusif sehingga dapat menggugah rasa penasaran peserta didik. Jika guru mampu memancing rasa penasaran peserta didik terhadap materi yang diajarkan maka tidak sulit bagi guru nantinya untuk membuat peserta didik memahami materi tersebut. Tentu saja metode yang diterapkan guru tersebut harus disesuaikan dengan karakteristik peserta didik, selain itu guru juga harus menerapkan pembelajaran yang berorientasi pada abad 21, TPACK dan HOTs.

Sebagai proses yang mengharuskan adanya interaksi timbal balik guru dan peserta didik, proses pembelajaran bisa dilakukan baik secara langsung melalui pembelajaran luring di kelas meskipun secara tidak langsung dengan sistem daring dengan menggunakan media pembelajar-an. Arsyad (2007) menyatakan bahwa dalam kegiatan belajar mengajar atau KBM adanya metode dan media pembelajaran merupakan dua hal yang krusial. Metode pembelajaran merupakan cara yang guru lakukan atau gunakan untuk mewujudkan tujuan pembelajaran sesuai yang sudah direncanakan dalam Rencana Pelaksanaan Pembelajaran atau RPP. Sedangkan media pembelajaran adalah teknologi pembawa pesan yang yang digunakan oleh guru guna kepentingan pembelajaran. Media digunakan sebagai alat bantu supaya peserta didik bisa memahami dan menyerap secara optimal materi yang diajarkan oleh guru dalam proses pembelajaran (Rusman, 2017).

Senada dengan Rusman, Sahid menyatakan bahwa media pembelajaran diibaratkan sebagai jembatan agar peserta didik diharapkan tidak kesulitan dalam menerima pembelajaran atau penjelasan materi yang dilakukan guru. Adanya implementasi media pembelajaran berbasis information technology diharapkan peserta didik dimudahkan dalam proses pembelajaran. Adanya pemanfaatan media berbasis information technology pada proses pembelajaran diharapkan bisa membuat suasana belajar menjadi kondusif, berjalan efektif serta efisien dan merangsang peserta didik untuk berfikir kritis.

Melalui wawancara yang dilakukan oleh CNN (2020), Salim menyatakan ada tiga aspek permasalah yang dialami guru di Indonesia yaitu masalah kualitas guru, kesejahteraan, sampai perlindungan keamanan. Terkait permasalah kualitas guru aspek yang harus dibenahi bukan hanya dari guru tetapi Lembaga Pendidikan dan Tenaga Kependidikan atau LPTK yang notabennya menjadi basis satuan yang melatih calon guru sebagai tenaga profesional.

Revina (2020) menyatakan bahwa Indonesia tengah mengalami darurat pendidikan. Salah satu sumber buruknya pendidikan di Indonesia terkait dengan kualitas guru. Hal yang menyebabkan rendahnya kualitas guru dikarenakan susahnya melakukan filter terhadap guru yang tidak mempunyai passion atau ketertarikan mengajar, tidak melihat 
Jurnal PINUS: Jurnal Penelitian Inovasi Pembelajaran, 7 (1), 2021, Rose Fitria Lutfiana

kebutuhan lapangan, dan tidak memperhatikan kecakapan kerja guru.

\section{METODE}

Pendekatan Pendekatan penelitian yang dipilih adalah kualitatif dengan jenis deskriptif. Lokasi penelitian yaitu di SMP Muhammadiyah 8 Kota Batu selama kurang lebih tiga bulan. Informan dalam penelitian ini adalah kepala sekolah dan guru-guru di SMP Muhammadiyah 8 Kota Batu.

Dalam penelitian kualitatif ini, teknik pengumpulan data yang digunakan oleh peneliti meliputi wawancara, observasi dan studi dokumentasi. Sedangkan instrument penelitian yang digunakan selain peneliti sendiri bertindak sebagai key instrument atau instrumen kunci juga ada pedoman wawancara, pedoman observasi dan pedoman studi dokumentasi.

Proses analisis data menggunakan teknik Milles Huberman yang terdiri dari empat tahap yaitu pengambilan data, reduksi data, display data dan kesimpulan. Seperti yang terlihat pada gambar 1 di bawah ini.

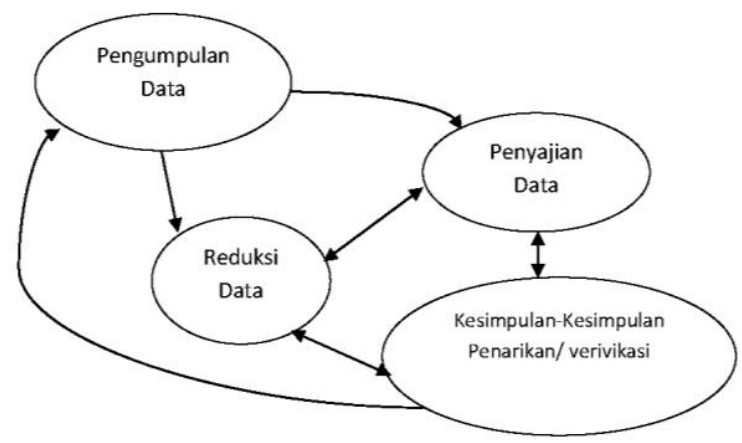

Gambar 1 Teknik analisis Milles Huberman

Penelitian ini menggunakan uji keabsahan data berupa triangulasi dan member check. Menurut Sugiyono (2017) uji keabsahan data perlu dilakukan sebagai bentuk pembuktian terhadap penelitian yang dilakukan, apakah benar bahwa penelitian tersebut merupakan penelitian ilmiah, selain itu uji keabsahan data juga digunakan untuk menguji data yang telah diperoleh.

\section{HASIL DAN PEMBAHASAN HASIL}

SMP Muhammadiyah 1 Kota Batu terletak di di Jalan Welirang No. 17 Kota Batu. Sekolah memiliki motto islami, kreatif, berkarakter, visinya yaitu "Terwujudnya sekolah Khas, Unggul dan Mandiri dengan mengacu kepada nilainilai islam berstandar Al-Qur'an dan AsSunah", sedangkan misinya meliputi: (a) mengembangkan pembelajaran yang khas dengan mengaitkan nilai-nilai keIslaman pada semua mata pelajaran; (b) mengembangkan budaya dan lingkungan sekolah yang bernuansa islami dengan pembiasaan amalan AsSunah; (c) mengembangkan lingkungan sekolah yang asri dengan penetaan tanaman dan ruangan yang ramah lingkungan; (d) meningkatkan pengembangan kurikulum yang berorientasi pada keunggulan potensi lokal; (e) meningkatkan kualitas dan kompetensi sumber daya manusia dengan mengembangkan pengetahuan, kemampuan, ketrampilan dan akhlakul karimah; (f) meningkatkan prestasi akademik dengan memaksimalkan atau menaikkan proses pembelajaran dan kriteria ketuntasan minimal (KKM); (g) meningkatkan prestasi non akademik dengan mengoptimalkan pembinaan kegiatan ektrakurikuler yang berkualitas; dan (h) meningkatkan kemandirian dan 
Jurnal PINUS: Jurnal Penelitian Inovasi Pembelajaran, 7 (1), 2021, Rose Fitria Lutfiana

efektivitas pengelolaan manajemen sekolah yang profesional dengan mengoptimalkan penerapan Manajemen Berbasis Sekolah (MBS).

SMP Muhammadiyah 8 Kota Batu memiliki guru yang berjumlah 43 orang yang mengampu mata pelajaran $\mathrm{Al}$ Islam, PPKn, bahasa Indonesia, Matematika, IPA, Bahasa Inggris, Seni Budaya, PJOK, Prakarya, Kemuhamadiyahan, Bahasa Arab, Bahasa Jawa, BK dan Tahfid. Untuk lebih jelas memahami perbandingan keduanya akan ditampilkan dalam bentuk diagram 1 di bawah ini.

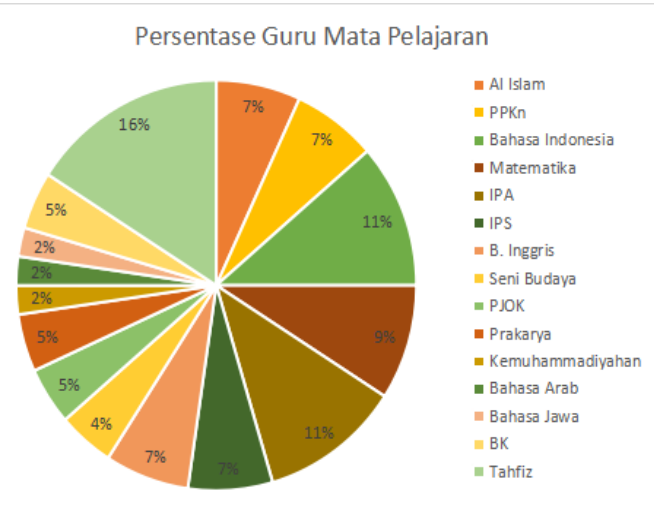

Diagram 1 Perbandingan Jumlah Guru Mata Pelajaran

Berdasarkan tabel di atas guru yang mengampu mata pelajaran Al Islam sebesar 7\% atau 3 orang, PPKn sebesar $7 \%$ atau 3 oarang, Bahasa Indonesia sebesar $11 \%$ atau 5 orang, Matematika sebesar $9 \%$ atau 4 orang, IPA sebesar $11 \%$ atau 5 orang, IPS sebesar $7 \%$ atau 3 orang, Bahasa Inggris sebesar $7 \%$ atau 3 orang, Seni Budaya sebesar $4 \%$ atau 2 orang, PJOK sebesar 5\% atau 2 orang, Prakarya sebesar $5 \%$ atau 2 orang, Kemuhammadiyahan sebesar $2 \%$ atau 1 orang, Bahasa Arab sebesar 2\% atau 1 orang, Bahasa Jawa sebesar $2 \%$ atau 1 orang, BK sebesar 5\% atau 2 orang dan Tahfiz sebesar $16 \%$ atau 7 orang.

Berdasarkan hasil penelitian yang dilakukan di SMP Muhammadiyah 8 Kota Batu terkait persentase jumlah guru yang menggunakan media dalam pembelajaran sebesar $88 \%$ sedangkan yang membuat atau menciptakan media pembelajaran sebesar $12 \%$. Untuk lebih jelas memahami perbandingan keduanya akan ditampilkan dalam bentuk diagram 2 di bawah ini.

Media Pembelajaran Berbasis Information Technology

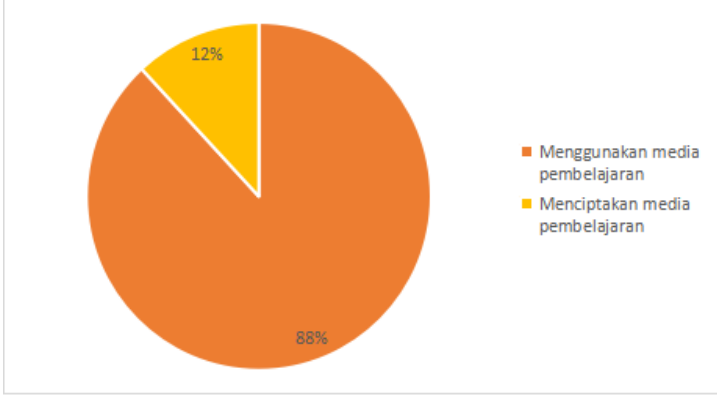

Diagram 2 Penggunaan Media Pembelajaran Berbasis IT

Hasil penelitian terkait pemanfaatan media pembelajaran sebanyak $17 \%$ menggunakan WAG, $37 \%$ menggunakan office $365, \quad 23 \%$ menggunakan edmodo dan $23 \%$ menggunakan google classroom. Untuk lebih jelas memahami perbandingannya akan ditampilkan dalam bentuk diagram 3 di bawah ini

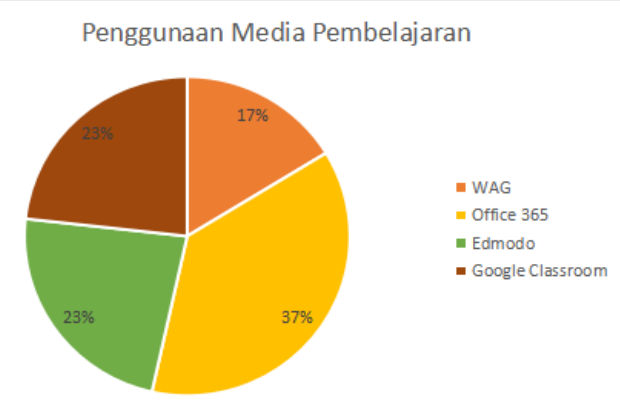

Diagram 3 Penggunaan Media Pembelajaran 
Hasil penelitian terkait guru yang menciptakan media pembelajaran sebanyak $36 \%$ membuat video pembelajaran, $17 \%$ membuat kuis dengan aplikasi quizis serta $47 \%$ membuat media PPT. Untuk lebih jelas memahami perbandingannya akan ditampilkan dalam bentuk diagram 4 di bawah ini.

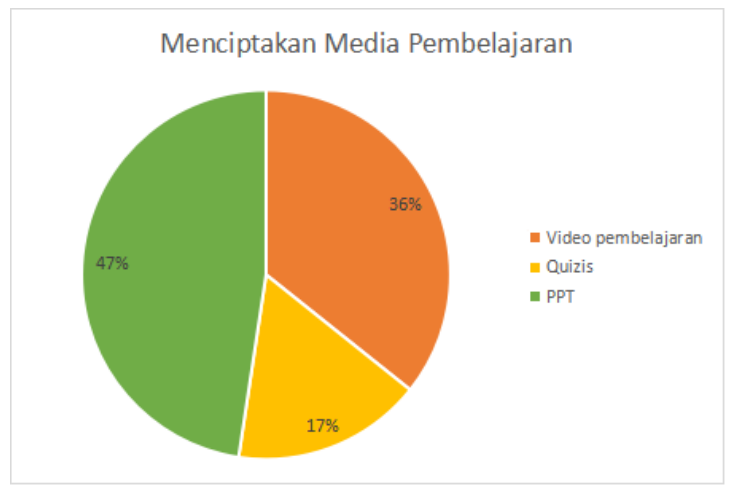

Diagram 4 Menciptakan Media Pembelajaran

Kemampuan guru terkait media pembelajaran meningkat sejak adanya pandemi yang mengharuskan sistem pembelajaran dari luring atau dikelas menjadi daring (online). Hal tersebut mau tidak mau memaksa para guru untuk melakukan penyesuaian. Sebelum pandemi hanya sebanyak $7 \%$ guru yang menggunakan media pembelajaran berbasis information technology, sedangkan saat pandemi sebanyak $100 \%$ guru dalam setiap pembelajaran memanfaatkan media dalam setiap kegiatan pembelajaran yang dilakukan.

\section{PEMBAHASAN}

Kompetensi profesional berkaitan dengan upaya guru yang mempunyai komitmen untuk menyelesaikan tugastugas keguruannya. Dalam UndangUndang Nomor 14 Tahun 2005 disebutkan yang termasuk dalam kompetensi profesional meliputi kemampuan penguasaan guru terhadap landasan kependidikan, penguasaan dalam bidang psikologi pendidikan, menguasai materi pembelajaran yang koheren dengan bidang studi yang diajarkan, kemampuan merancang dan memanfaatkan media dan sumber belajar, dan kemampuan melaksanakan proses evaluasi.

Kemampuan penguasaan guru terhadap landasan kependidikan. Hal ini mengandung artian seorang guru harus mengerti tentang berbagai kebijakan dan praktik pendidikan. Landasan pendidikan meliputi landasan filosofis, sosiologis, yuridis dan kultural. Landasan filosofis dari pendidikan sendiri tidak lepas dari tiga unsur bidang kajian yang terdiri dari kajian ontologi, epistimologis dan aksiologis dari pendidikan. Landasan sosiologis berkaitan dengan kejelian pendidik atau guru dalam memahami persoalan-persoalan sosial baik yang terjadi pada individu dan masyarakat yang mempunyai akibat atau implikasi pada bidang pendidikan. Landasan yuridis bisa kita lihat dari adanya peraturan perundang-undangan yang berkaitan dengan pendidikan seperti UUD NRI Tahun 1945, Undang-Undang Nomor 20 Tahun 2003 tentang Sistem Pendidikan Nasional dan juga berbagai peraturan lain. Urgensi seorang guru menguasai landasan pendidikan tidak lepas dari hakikat pendidikan yang merupakan suatu proses perubahan yang terjadi pada diri individu dari tidak tau menjadi tau, bahkan lebih jauh dari itu menurut Driyarkara pendidikan adalah proses memanusiakan manusia. 
Jurnal PINUS: Jurnal Penelitian Inovasi Pembelajaran, 7 (1), 2021, Rose Fitria Lutfiana

\begin{abstract}
Penguasaan dalam bidang psikologi pendidikan. Psikologi pendidikan berkaitan erat dengan respon kejiwaan dan tingkah laku peserta didik dalam proses pembelajaran. Guru harus mempunyai kemampuan memahami psikologi pendidikan agar proses pembelajaran yang terjadi bisa berjalan secara efektif, mengingat setiap peserta didik memiliki cara belajar ataupun memahami atau menyerap materi dengan tingkatan yang berbeda-beda. Penguasaan psikologi peserta didik didapatkan dan dipelajari oleh guru saat menempuh proses pendidikan, namun implementasi dari ilmu tersebut bisa diterapkan saat sudah menjadi seorang guru.
\end{abstract}

Guru menguasai materi
pembelajaran yang koheren dengan
bidang studi yang diajarkan. Guru harus
mengajar sesuai dengan bidang ilmunya. Hal ini sangat berhubungan dengan profesionalitas, serta kredibilitas guru dalam penguasaan pengetahuan. Penguasaan materi pembelajaran terlihat dari sinergitas mata pelajaran yang diampu dan konsentrasi pendidikan yang ditempuh oleh seorang guru. Contoh seseorang yang menempuh jenjang sarjana Pendidikan Matematika maka juga mengajar Pendidikan Matematika. Berdasarkan hasil penelitian yang dilakukan $100 \%$ guru di SMP Muhammadiyah 8 Batu mengajar sesuai dengan bidangnya.

Kemampuan

dalam

mengaplikasikan berbagai metode dan strategi pembelajaran. Implementasi metode dan juga strategi pembelajaran harus disesuaikan dengan materi dan juga karakteristik peserta didik yang diajar. Guru tentu saja harus mampu menganalisa situasi terkait ketepatan dalam pemilihan metode ataupun strategi pembelajaran yang digunakan. Berdasarkan hasil penelitian guru di SMP Muhammadiyah 8 Batu biasa menerapkan pendekatan saintifik dan TPACK.

Kemampuan merancang dan memanfaatkan media dan sumber belajar. Sesuai dengan pembelajaran abad 21 dan juga pembelajaran berbasis TPACK semua guru wajib mengimplementasikan media dalam kegiatan pembelajaran. Selain itu pemanfaatan sumber belajar yang kekinian juga harus diimplementasikan dalam pembelajaran. Sumber belajar bukan hanya berupa buku cetak ataupun LKS, peserta didik bisa dikenalkan dengan sumber referensi digital yang lebih menarik.

Kemampuan melaksanakan proses evaluasi. Evaluasi penting dilakukan oleh guru untuk mengetahui tingkat ketercapaian tujuan pembelajaran yang telah dirumuskan oleh guru. Guru harus mampu membuat istrumen evaluasi berbasis HOTs. Guru juga harus memiliki kemampuan menyusun program pembelajaran. Program pembelajaran memberikan gambaran pasti tentang apaapa yang akan dilakukan selama satu tahun, satu semester bahkan sampai tingkat paling rigit satu hari.

Pemaparan di atas juga sejalan dengan pendapat Nurtanto (2019) bahwa kompetensi profesional guru berhubungan dengan kemampuan penguasaan materi pembelajaran secara universal dan holistik yang 
Jurnal PINUS: Jurnal Penelitian Inovasi Pembelajaran, 7 (1), 2021, Rose Fitria Lutfiana

memungkinkan membimbing peserta didik memenuhi standar kompetensi. Kompetensi profesional meliputi sub kompetensi: (1) menguasai substansi bidang studi dan metodologi keilmuannya, (2) menguasai struktur dan materi kurikulum bidang studi, (3) menguasai dan memanfaatkan teknologi informasi dan komunikasi dalam pembelajaran, (4) mengorganisasikan materi kurikulum bidang studi, (5) meningkatkan kualitas pembelajaran melalui penelitian tindakan kelas

Terkait dengan kemampuan penggunaan media atau kemampuan guru dalam menciptakan sebuah media dalam pembelajaran merupakan hal yang sangat penting. Dari hasil penelitian diperoleh data bahwa sebelum pandemi pandemi hanya sebanyak $7 \%$ guru yang menggunakan media pembelajaran berbasis information technology, sedangkan saat pandemi sebanyak 100\% guru dalam setiap pembelajaran memanfaatkan media.

Media dalam proses pembelajaran merupakan salah satu aspek yang mempengaruhi keberhasilan. Hal ini seperti yang diungkapkan oleh Gagne bahwa media yang digunakan dalam pembelajan bisa jadi memberikan stimulus atau rangsangan bagi peserta didik untuk belajar. Hal ini juga sejalan dengan hasil penelitian yang dilakukan oleh Adhe (2018) yaitu media pembelajaran membuat mahasiswa tertarik untuk melakukan proses pembelajaran. Selain itu hasil riset dari Nurhayati (2020) tentang penggunaan quiziz dalam meningkatkan keaktifan siswa terbukti sebesar $17,65 \%$.

\section{KESIMPULAN}

Hasil penelitian yang diperoleh yaitu: (a) guru mampu melakukan pengelolaan pembelajaran berbasis information technology seperti edmodo, office 365, google classroom, dan $W A G$; dan (b) guru mampu merancang berbagai media pembelajaran berbasis information technology yang digunakan dalam pembelajaran seperti membuat video pembelajaran, membuat kuis dengan aplikasi quizzes dan PPT.

\section{DAFTAR RUJUKAN}

Adhe, Kartika Rinakit. 2018. Pengembangan Media Pembelajaran Daring Mata Kuliah Kajian PAUD Di Jurusan PG PAUD Fakultas Ilmu Pendidikan Universitas Negeri Surabaya. Journal of Early Childhood Care and Education, 1 (1), hal 26-31

Anonim. 2020. Landasan Pendidikan. (online) https://teks.co.id/landasanpendidikan/

Arsyad Azhar. 2007. Media Pembelajaran. Jakarta: PT Raja Grafindo Persada.

CNN. 2020. Asosiasi Ungkap Akar Masalah Guru: Lembaga Pendidik dan Upah. (online) https://www.cnnindonesia.com/nasi onal/20201126105315-20-

574704/asosiasi-ungkap-akarmasalah-guru-lembaga-pendidikdan-upah

Dudung, Agus. (2018). Kompetensi Profesional Guru. Jurnal Kesejahteraan Keluarga dan Pendidikan, 5 (1), 9-19 https://doi.org/10.21009/JKKP.051. $\underline{02}$

Fitriani, Cut; A.R, Murniati dan Usman, Nasir. 2017. Kompetensi Profesional Guru Dalam Pengelolaan Pembelajaran Di MTs 
Jurnal PINUS: Jurnal Penelitian Inovasi Pembelajaran, 7 (1), 2021, Rose Fitria Lutfiana

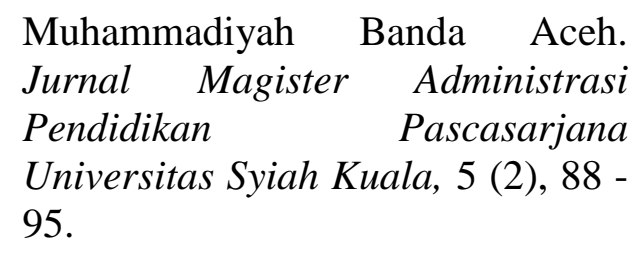

Marwiyah, St; Alauddin dan BK, Muh. Kaerul Ummah. 2018. Perencanaan Pembelajaran Kontemporer Berbasis Penerapan Kurikulum 2013. Yogyakarta: Deepublish.

Nurhayati, Erlis. 2020. Meningkatkan Keaktivan Siswa Dalam Pembelajaran Daring Melalui Media Game Quizzis Pada Masa Pencegahan Penyebaran Covid 19. Jurnal Paedagogy, 7 (3), 145-150

Nurtanto, Muhammad. (2019). Mengembangkan Kompetensi Profesionalitas Guru Dalam Menyiapkan Pembelajaran Yang Bermutu. Prosiding Seminar Nasional Inovasi Pendidikan, 553565

https://jurnal.fkip.uns.ac.id/index.ph p/snip/article/viewFile/8975/6535

Revina, Shintia. 2020. Mengapa Kualitas Guru Di Indonesia Masih Rendah?. (online)

https://magdalene.co/story/mengapa -kualitas-guru-di-indonesia-masihrendah

Rusman, 2017. Belajar Pembelajaran Berorientasi Standar Proses Pendidikan. Jakarta: Prenada media grup.

Sahid. Pengembangan Media Pembelajaran Berbasis ICT. (online)

http://staffnew.uny.ac.id/upload/131 930136/penelitian/Pengembangan+ Media+Pembelajaran+Berbasis $+\mathrm{IC}$ T.pdf

Sugiyono. (2017). Metode Penelitian Kualitatif. Untuk Penelitian yang Bersifat: Eksploratif, Enterpretif, Interaktif, dan Konstruktif. Bandung: Alfabeta.
Undang-undang No 14 Tahun 2005 Tentang Guru dan Dosen

Wahyudi, I. (2012), Pengembangan Pendidikan, Strategi Inovatif \& Kreatif Dalam Mengelola Pendidikan Secara Konprehensif, PT. Prestasi, Jakarta.

rland, J. H. (2005). Gifted education without gifted children: The case for no conception of giftedness. In Conceptions of Giftedness: Second Edition.

https://doi.org/10.1017/CBO978051 1610455.002

Clikeman, M.S. (2007). Social Competence in Children. Springer Science and Business Media.

De França-Freitas, M. L. P., Del Prette, A., \& Del Prette, Z. A. P. (2015). Social skills of gifted and talented children. Estudos de Psicologia, 19(4).

https://doi.org/10.1590/s1413-

294x2014000400006

Jackson, P. S., Moyle, V. F., \& Piechowski, M. M. (2009). Emotional Life and Psychotherapy of the Gifted in Light of Dabrowski's Theory. In International Handbook on Giftedness.

https://doi.org/10.1007/978-1-40206162-2_20

Johnson, W. D. (2009). Reaching Out: Interpersonal Effectiveness and Actualization. Pearson Education.

Jones, T. S. (2004). Conflict resolution education: The field, the findings, and the future. Conflict Resolution Quarterly, 22(1-2). https://doi.org/10.1002/crq.100

Morton Deutsch, Peter T. Coleman, E. C. M. (2006). The Handbook of Conflict Resolution: Theory and Practice. John Wiley and Sons Inc.

Munandar,Utami. (2009). Pengembangan Kreativitas Anak 
Jurnal PINUS: Jurnal Penelitian Inovasi Pembelajaran, 7 (1), 2021, Rose Fitria Lutfiana

Berbakat. Rineka Cipta.

Nawantara, R. D. (2016). Perbedaan Keterampilan Memecahkan Konflik Interpersonal Antara Siswa Kelas Akselerasi Dan Siswa Kelas Reguler Di SMAN RSBI Se-Kota Malang. Nusantara of Research: Jurnal Hasil-Hasil Penelitian Universitas Nusantara PGRI Kediri, 3(1).

Nawantara, R. D. (2017). Interpersonal Conflict Resolution Skill (Solusi Konstrukstif Bagi Konflik Interpersonal Siswa). Seminar Nasional Bimbingan Konseling Universitas Ahmad Dahlan.

Porter, L. (2005). Gifted Young Children: Meeting Their Needs. Early Childhood Australia Inc.

Sugiarti, Rini., Suhariadi, Fendi. (2015). Gambaran Kompetensi Sosial Siswa Cerdas Istimewa. Seminar Psikologi \& Kemanusiaan. 